\title{
Density Functional and Ab Initio Studies on Structures and Energies of the Ground State of $\mathrm{CrCO}$
}

\author{
JOONGHAN KIM, YOON SUP LEE, HYOTCHERL IHEE \\ Department of Chemistry and School of Molecular Science (BK21), Korea Advanced Institute of \\ Science and Technology (KAIST), Daejeon, 305-701, Republic of Korea
}

Received 3 April 2006; Accepted 19 April 2006

Published online 13 September 2006 in Wiley InterScience (www.interscience.wiley.com). DOI 10.1002/qua.21099

\begin{abstract}
CrCO}$ was studied using density functional theory (DFT) and ab initio methods. We obtained the two-dimensional potential energy surface (PES), geometry, and vibrational frequencies for $\mathrm{CrCO}$ in a septet state. Two minimum structures were found in the $\operatorname{CCSD}(\mathrm{T})$ calculation, including a local minimum that is a weak van der Waals (vdW) complex. All DFT methods yield only one minimum structure. We demonstrate that the bond dissociation energy $(0.50 \mathrm{kcal} / \mathrm{mol})$ and vibrational frequency $\left(1981.1 \mathrm{~cm}^{-1}\right)$ of $\mathrm{CrCO}$ calculated using CCSD(T) are in better agreement with experimental values $\left(<1.5 \mathrm{kcal} / \mathrm{mol}\right.$ and $\left.1977 \mathrm{~cm}^{-1}\right)$ than any of the reported theoretical studies. (c) 2006 Wiley Periodicals, Inc. Int J Quantum Chem 107: 458-463, 2007
\end{abstract}

Key words: density functional theory; ab initio; chromium carbonyl; potential energy surface; bond dissociation energy

\section{Introduction}

$\mathbf{T}$ he transition metal carbonyl compounds, $\mathrm{M}(\mathrm{CO})_{n}$, serve as building blocks in organometallic chemistry, and play important roles in heterogeneous catalysis. To understand the mechanism of such catalytic activity and to improve the

Correspondence to: H. Ihee; e-mail: hyotcherl.ihee@kaist.ac.kr Contract grant sponsor: Korea Science and Engineering Foundation/Nano R\&D Program.

Contract grant number: 2005-02638.

Contract grant sponsor: Ministry of Science and Technology.

Contract grant numbers: M102KN010010-05K1401-01010. design of better catalysts, the nature of the intermediates involved in the reaction should be known. Toward this goal, there have been numerous experimental [1-3] and theoretical investigations [4, 5].

One of the simplest cases of $\mathrm{M}(\mathrm{CO})_{n}$ is $\mathrm{CrCO}$. There have been many investigations of $\mathrm{CrCO}$, using density functional theory (DFT) [6-10] and ab initio $[11,12]$ methods. Although $\mathrm{CrCO}$ is a simple system, accurate information is not available about the ground state of $\mathrm{CrCO}$. For the lowest-energy state of $\mathrm{CrCO}$, DFT and ab initio methods have provided results contrary to each other. The former gave a bent structure with septet [6-10] and the latter a linear structure with septet $[11,12]$. In ad- 


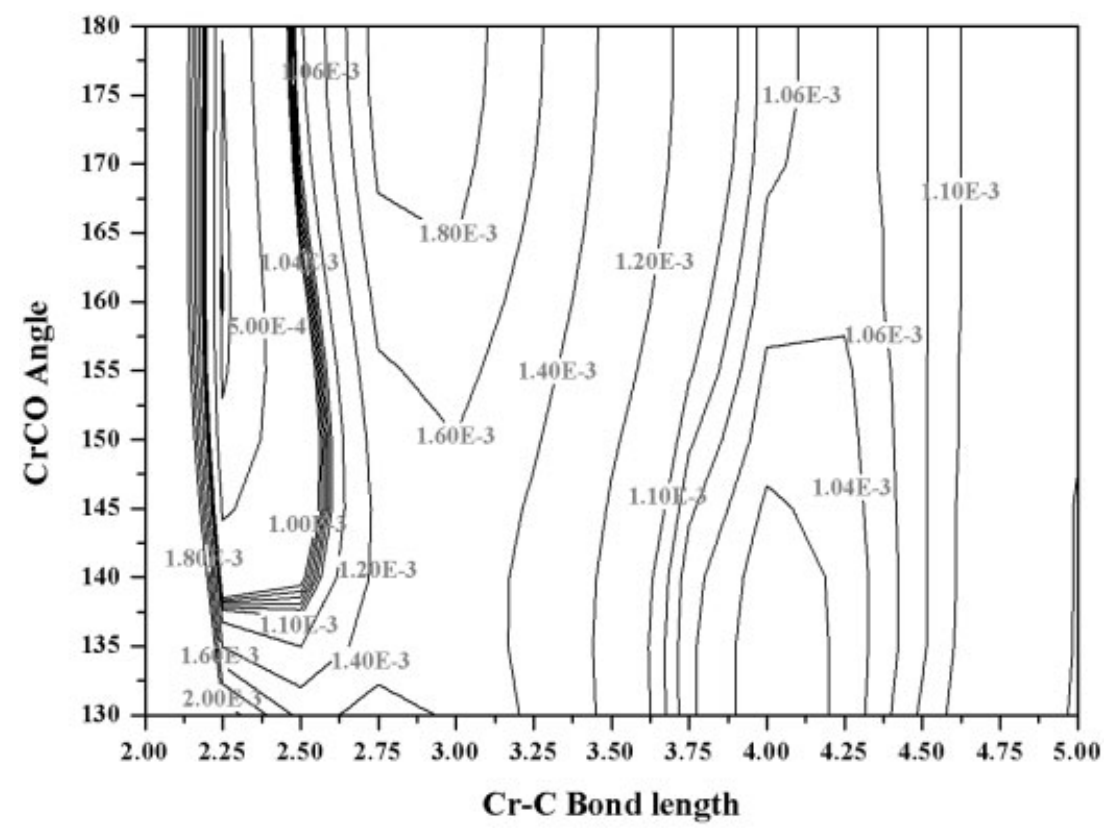

FIGURE 1. PES (hartree) using $\operatorname{CCSD}(T) / 6-311+G(3 d f)$ and fixing $C-O$ distance $(1.133 \AA$ ). The minimum is located at near $2.25 \AA$ of $\mathrm{Cr}-\mathrm{C}$ distance and $160^{\circ}$ of $\angle \mathrm{CrCO}$ angle; the other is located at near $4.00 \AA$ of $\mathrm{Cr}-\mathrm{C}$ distance and $135^{\circ}$ of $\angle \mathrm{CrCO}$ angle.

dition, most studies did not provide vibrational frequencies and the bond dissociation energy (BDE) including proper basis set superposition error (BSSE) correction. For a few studies providing such information, calculated values did not reproduce the experiment value well. It is difficult to reproduce the $\mathrm{BDE}$ of $\mathrm{CrCO}$ theoretically because the experimental $\mathrm{BDE}$ of $\mathrm{CrCO}$ is very small value $(<1.5 \mathrm{kcal} / \mathrm{mol})$ [13]. Recently $\mathrm{CrCO}$ was investigated by the $\operatorname{CCSD}(\mathrm{T})$ method [14]. This result shows that $\mathrm{CrCO}$ is bent and a septet, which is the same as the result of DFT calculation. Since the study did not provide any frequency information, one cannot confirm that the structure was at a stationary point. To resolve this issue, the potential energy surface (PES) and vibrational frequencies using higher-level calculations are of high demand. We systematically investigated these issues using the $\operatorname{CSSD}(\mathrm{T})$ method with a basis set of appropriate size.

\section{Computational Details}

We performed DFT calculations using hybrid functional (B3PW91 [15], B3P86 [15, 16], mPW1PW91 [17, 18], O3LYP [19]), GGA (BLYP [20, 21], BPW91
[18, 20], BP86 [16, 20], PBE [22], OLYP [23]) and LDA [24, 25]. In addition, we performed ab initio calculations, such as MP2 [26, 27], CCSD [28, 29], and $\operatorname{CCSD}(\mathrm{T})$ [30]. All ab initio calculations were performed with frozen-core approximation. All calculations have been carried out with the Gaussian 03W and Gaussian 03 program [31]. We used 6-311+G(3df) (Cr: (15s11p6d3f1g)/[10s7p4d3f1g], C and O: $(12 s 6 p 3 d 1 f) /[5 s 4 p 3 d 1 f]$ basis sets for most calculations. To locate the ground state of $\mathrm{CrCO}$, we scanned the ground-state PES of $\mathrm{CrCO}$ (fixing the distance of $\mathrm{C}-\mathrm{O}$ as $1.133 \AA$ ) using $\mathrm{B} 3 \mathrm{LYP} / 6$ $311+\mathrm{G}(3 d f), \operatorname{CCSD}(\mathrm{T}) / 6-311+\mathrm{G}(d)$, and $\operatorname{CCSD}(\mathrm{T}) / 6-$ $311+\mathrm{G}(3 d f)$. The results of $\operatorname{CCSD}(\mathrm{T}) / 6-311+\mathrm{G}(3 d f)$ and B3LYP/6-311+G(3df) are presented in Figures 1 and 2. In the PES of CrCO at the CCSD(T) level, we used both 6-311+G(3df) and 6-311+G $(d)(\mathrm{Cr}$ : $(15 s 11 p 6 d 1 f) /[10 s 7 p 4 d 1 f], C$ and O: $(12 s 6 p 1 d) /$ [5s4p1d]) basis sets. The molecular structures were fully optimized; harmonic vibrational frequencies have been calculated at the optimized geometries. The calculated BDE includes the corrections of zero-point energies (ZPE) and thermal enthalpy $(298 \mathrm{~K})$, and the BSSE corrected by the counterpoise method [32]. In the case of ab initio methods, we used $50 \%$ of the BSSE correction, following the suggestion that the magnitude of BSSE might be 


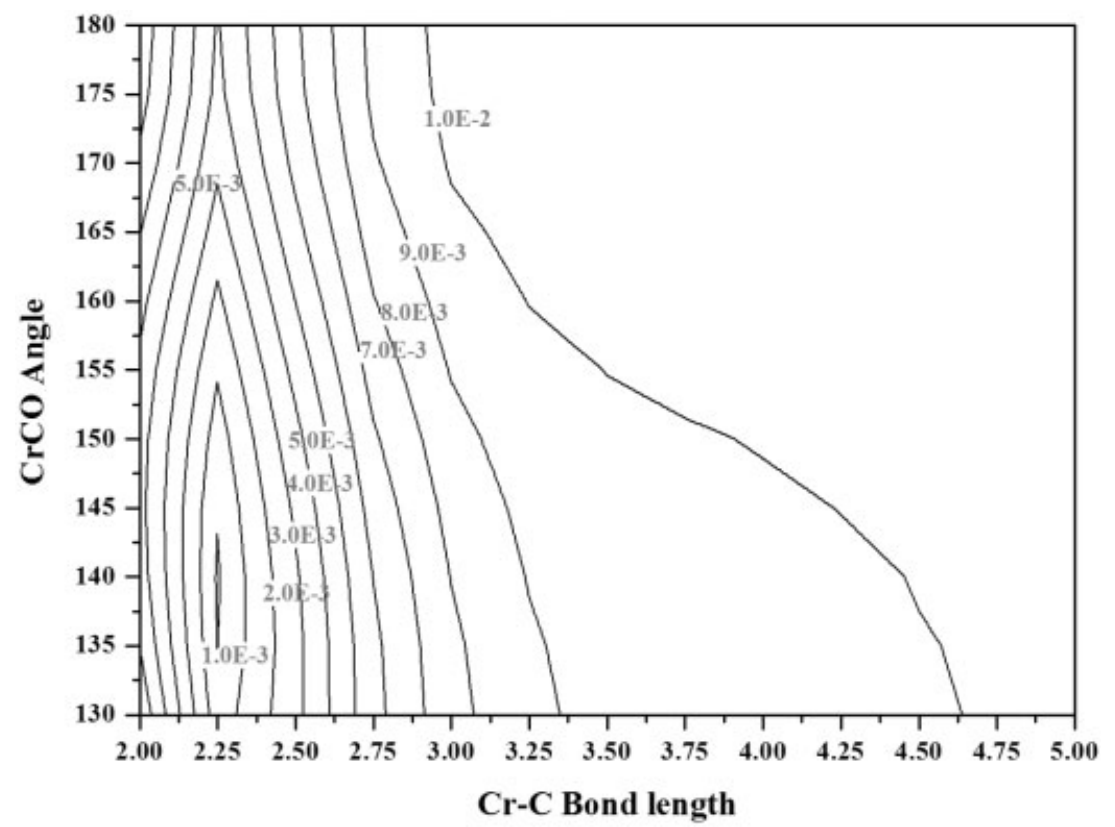

FIGURE 2. PES (hartree) using B3LYP/6-311+G(3df) and fixing $\mathrm{C}-\mathrm{O}$ distance $(1.133 \AA$ ). The minimum is located at near $2.25 \AA$ of $\mathrm{Cr}-\mathrm{C}$ distance and $140^{\circ}$ of $\angle \mathrm{CrCO}$ angle.

overestimated in the counterpoise method [33]. The calculated relative energies and enthalpies, BDE, fully optimized geometrical parameters are shown in Table I and vibrational frequencies in $\mathrm{CrCO}$ are shown in Table II.

\section{Results and Discussion}

\section{MOLECULAR STRUCTURES}

Experimentally, $\mathrm{CrCO}$ was detected in the Ar matrix at $4 \mathrm{~K}$ and the observed stretching frequency is $1977 \mathrm{~cm}^{-1}$ [34]. However, there is no other experimental structural information. Experimental evidence shows that the lowest-energy state of $\mathrm{CrCO}$ is septet and its dissociation energy is $<1.5 \mathrm{kcal} / \mathrm{mol}$ [13].

We scanned the PES of CrCO to clarify the accurate global minimum of CrCO. We used B3LYP/6$311+\mathrm{G}(3 d f), \operatorname{CCSD}(\mathrm{T}) / 6-311+\mathrm{G}(d)$, and $\operatorname{CCSD}(\mathrm{T}) /$ $6-311+\mathrm{G}(3 d f)$. The results of each method using the $6-311+\mathrm{G}(3 d f)$ basis set are presented in Figures 1 and 2. The PES of $\mathrm{CrCO}$ using $\operatorname{CCSD}(\mathrm{T}) / 6$ $311+\mathrm{G}(3 d f)$ is different from that using $\operatorname{CCSD}(\mathrm{T}) /$ $6-311+\mathrm{G}(d)$. The $\operatorname{CCSD}(\mathrm{T}) / 6-311+\mathrm{G}(d)$ result indicates that $\mathrm{CrCO}$ does not have a bound state near 2 $\AA$. Instead, near $4.25 \AA, \mathrm{CrCO}$ has a slightly bound state that is an extremely weak van der Waals (vdW) complex. In contrast the $\operatorname{CCSD}(\mathrm{T}) / 6$ -
$311+\mathrm{G}(3 d f)$ result is that $\mathrm{CrCO}$ has both the global minimum state near $2.25 \AA$ and the local minimum state near $4 \AA$. The $6-311+G(d)$ basis set does not properly describe the PES of $\mathrm{CrCO}$. As shown in Figure 2, the PES of B3LYP/6-311+G(3df) is completely different from the PES of $\operatorname{CCSD}(\mathrm{T}) / 6$ $311+G(3 d f)$. Both methods show that the lowestenergy has the $\mathrm{Cr}-\mathrm{C}$ bond length of near $2.25 \AA$ (see Figs. 1 and 2). However, the $\angle \mathrm{CrCO}$ angles are different (CCSD(T): near $160^{\circ}$, B3LYP: near $\left.140^{\circ}\right)$. In addition, B3LYP does not find the local minimum structure around a longer $\mathrm{Cr}-\mathrm{C}$ distance $(\sim 4 \AA)$.

Based on the scanned PES, we have carried out geometry optimization, and the results with the $6-311+\mathrm{G}(3 d f)$ basis set are presented in Tables I and II. All methods show that all bent structures have no imaginary frequency. In contrast, all linear structures have 2 imaginary frequencies. All calculations suggest that the bent structure is the ground state of CrCO. All DFT methods seem to overestimate the interaction between the $\mathrm{Cr}$ atom and the $\mathrm{C}$ atom as indicated from the large dissociation energy (see Table 1), and predict the shorter bond length of $\mathrm{Cr}-\mathrm{C}$. Although the molecular shape is correctly found to be bent in all DFT methods, the description of PES is not accurate. $\operatorname{CCSD}(\mathrm{T})$ shows that $\mathrm{CrCO}$ has a local minimum structure that is an extremely weak vdW complex. Its dissociation en- 


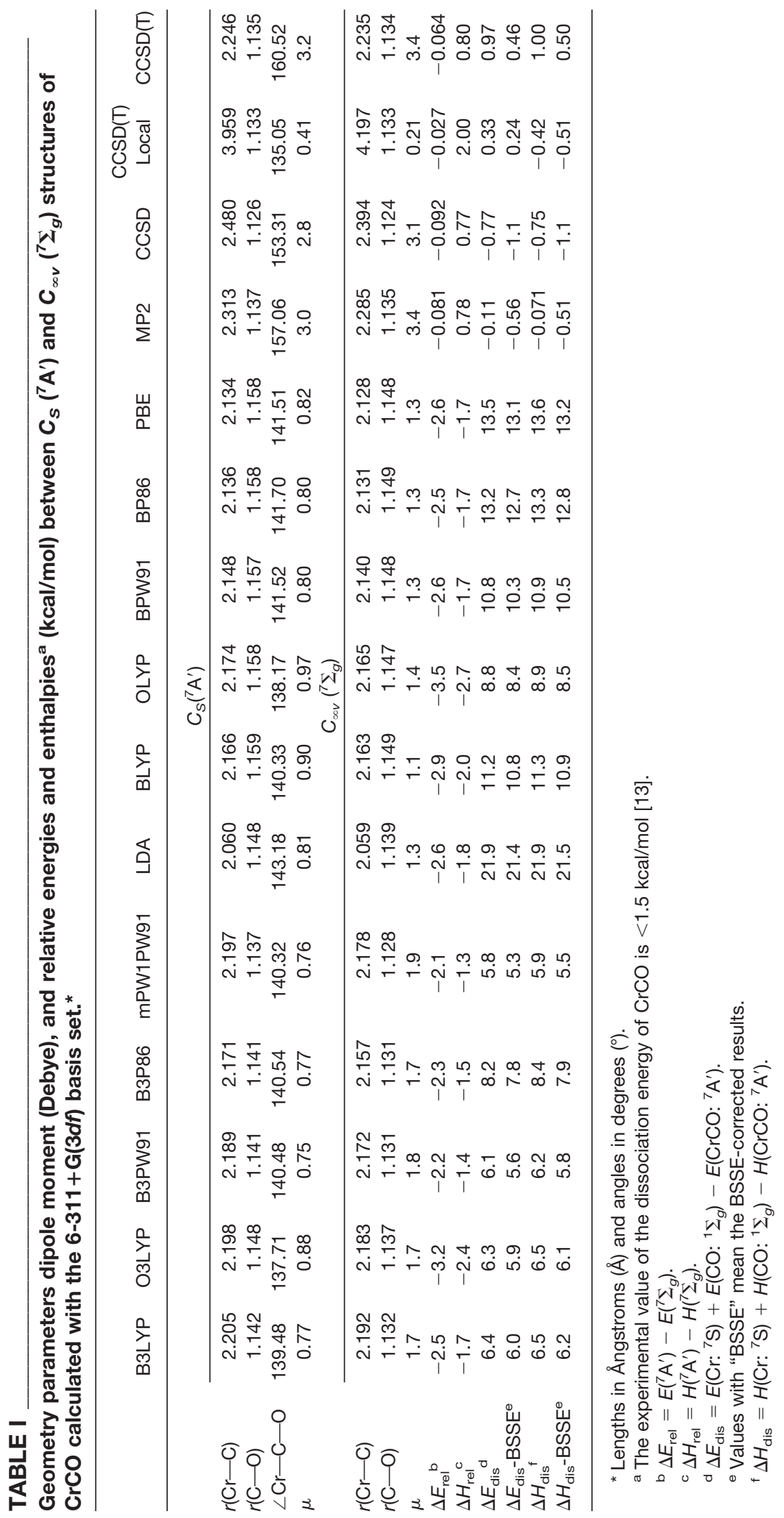




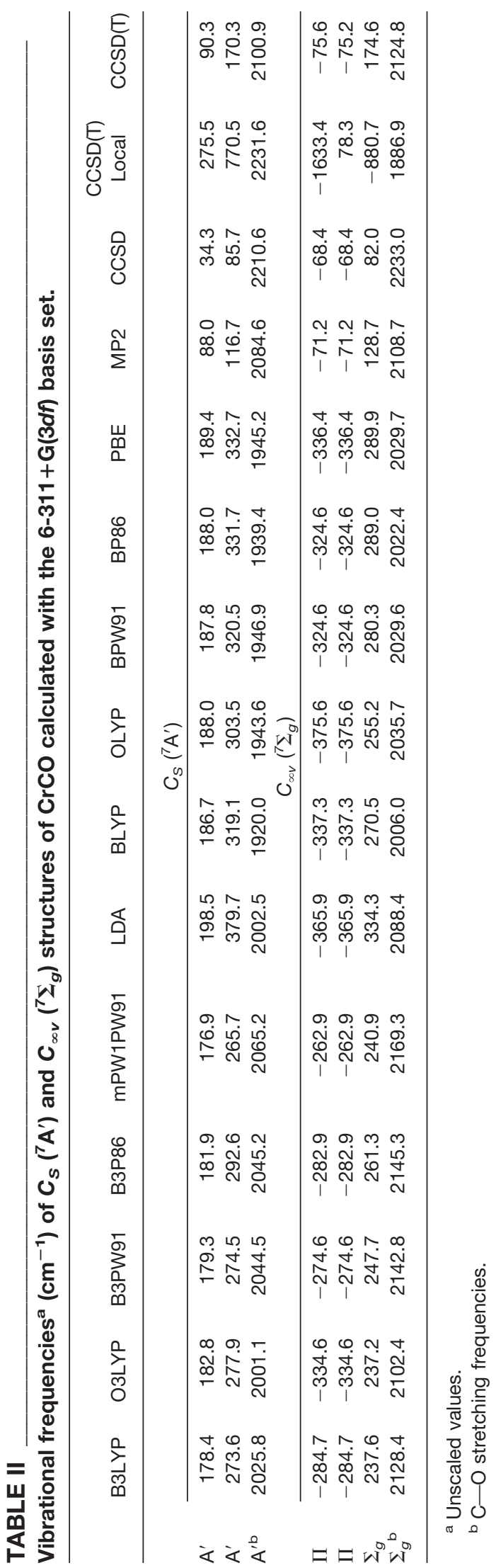

ergy is only $0.24 \mathrm{kcal} / \mathrm{mol}$ (see Table I). As shown in Figure 2, B3LYP does not provide a local minimum structure. All DFT methods are expected to follow the same trend, since the DFT methods are generally known to describe the vdW interaction poorly.

\section{VIBRATIONAL FREQUENCY}

The vibrational frequencies of $\mathrm{CrCO}$ using several ab initio methods and DFT with 6-311+G(3df) basis set are presented in Table II. We use the scale factors of 0.954 and 0.943 for CCSD/6-311+G(d) and $\operatorname{CCSD}(\mathrm{T}) / 6-311+\mathrm{G}(3 d f)$, respectively. These values are provided on the U. S. National Institute of Standard and Technology (NIST) web page (http:// srdata.nist.gov/cccbdb/). CCSD(T) method gives a value of $2100.9 \times 0.943=1981.1$, which is in excellent agreement with the experiment one (see Table II).

\section{BOND DISSOCIATION ENERGY (BDE)}

The $\mathrm{BDE}$ of the $\mathrm{CrCO}$ case using various ab initio methods and DFT, as well as the results, are also presented in Table I. All DFT methods overestimate the $\mathrm{BDE}$ of $\mathrm{CrCO}$. GGA methods in particular largely overestimate BDEs, with magnitudes approximately twice that of hybrid methods. The exact exchange term plays an important role in the thermochemical value. However, mixing exact exchange terms is not sufficient for a complete description of a vdW complex. CCSD and MP2 methods provide negative BDE values, implying the unbound state of $\mathrm{CrCO}$. Only a high-level ab initio method, such as $\operatorname{CCSD}(\mathrm{T})$ and a basis set of large size, can accurately describe the transition metal complex formed by weak interactions.

A previous $\operatorname{CCSD}(\mathrm{T})$ calculation gave a $\mathrm{BDE}$ value $\left(D_{0}\right)$ of $2 \mathrm{kcal} / \mathrm{mol}[14]$. However, this value is not the result of vibrational analysis, but is rather a "best" estimated value (see Ref. [14]). In addition, it is not corrected by BSSE, which is important for an accurate description of the BDE. We also emphasize that the experimental value of $\mathrm{BDE}$ of $\mathrm{CrCO}$ is not exactly $1.5 \mathrm{kcal} / \mathrm{mol}$, but rather $<1.5 \mathrm{kcal} / \mathrm{mol}$ [13]. In other words, the experiment gave only the upper limit of $1.5 \mathrm{kcal} / \mathrm{mol}$. The previous result of $\operatorname{CCSD}(\mathrm{T})$ $(2 \mathrm{kcal} / \mathrm{mol})$ is out of this range $(<1.5 \mathrm{kcal} / \mathrm{mol})$. Up to now, there has been no report of a calculated value that falls within the experimental range.

We performed a vibrational frequency calculation and added the BSSE correction using $\operatorname{CCSD}(\mathrm{T}) / 6-311+\mathrm{G}(3 d f)$. The results are presented in Table I. The BDE of CrCO is $0.50 \mathrm{kcal} / \mathrm{mol}(\Delta \mathrm{H}$, 
BSSE corrected value) at the $\operatorname{CCSD}(\mathrm{T}) / 6-311+\mathrm{G}(3 d f)$ level (see Table I). This value is within the experimental range of $<1.5 \mathrm{kcal} / \mathrm{mol}$. We also propose a local minimum energy state of $\mathrm{CrCO}$, which has a long $\mathrm{Cr}-\mathrm{C}$ distance $(3.959 \AA)$. Its BDE $(0.24 \mathrm{kcal} /$ $\mathrm{mol}$ ) is less than that, at $0.46 \mathrm{kcal} / \mathrm{mol}$ of the lowestenergy state (see Table I).

\section{Conclusions}

We calculated optimized geometries, $\mathrm{C}-\mathrm{O}$ stretching frequencies, and $\mathrm{BDE}$ of $\mathrm{CrCO}$ using various DFT and ab initio methods with the 6-311 $+\mathrm{G}(3 d f)$ basis set. According to the $\operatorname{CCSD}(\mathrm{T}) /$ $6-311+G(3 d f)$ calculation, the lowest-energy state of $\mathrm{CrCO}$ is "bent" with septet; a local minimum structure that is a weak vdW complex was also identified. $\operatorname{CCSD}(\mathrm{T}) / 6-311+\mathrm{G}(3 d f), \mathrm{BDE}$, and vibrational frequencies of $\mathrm{CrCO}$ are in excellent agreement with the experimental values. Although DFT methods give a ground structure similar to that found with the $\operatorname{CCSD}(\mathrm{T})$ method, they produce a significantly different PES at weak interaction region because of the deficiency in the description of vdW interactions due to the inadequacy of all DFT methods, including hybrid methods, in describing vdW interactions.

\section{ACKNOWLEDGMENTS}

This work was supported by Korea Science and Engineering Foundation Nano R\&D Program Grant 2005-02638. The one of the authors (Y. S. L.) was supported by the Ministry of Science and Technology (Korea Center for Nanoscale Mechtronics and Manufacturing, 21st Century Frontier Research Program), grant M102KN010010-05K1401-01010.

\section{References}

1. Ihee, H.; Lobastov, V. A.; Gomez, U. M.; Goodson, B. M.; Srinivasan, R.; Ruan, C.-Y.; Zewail, A. H. Science 2001, 291, 458.

2. Siwick, B. J.; Dwyer, J. R.; Jordan, R. E.; Miller, R. J. D. Science 2003, 302, 1382.

3. Ruan, C.-Y.; Lobastov, V. A.; Vigliotti, F.; Chen, S.; Zewail, A. H. Science 2004, 304, 80.

4. Niu, S.; Thomson, L. M.; Hall, M. B. J Am Chem Soc 1999 , 121, 4000.

5. Fraile, J. M.; Garcia, J. I.; Martinez-Merino, V.; Mayoral, J. A.; Salvatella, L. J Am Chem Soc 2001, 123, 7616.

6. Fournier, R. J Chem Phys 1993, 99, 1801.

7. Fournier, R. J Chem Phys 1993, 98, 8041.
8. Adamo, C.; Lelj, F. J Chem Phys 1995, 103, 10605.

9. Andrews, L.; Zhou, M.; Gutsev, G. L.; Wang, X. J Phys Chem A 2003, 107, 561.

10. Pilme, J.; Silvi, B. J Phys Chem A 2003, 107, 4506.

11. Jeung, G.-H. J Am Chem Soc 1992, 114, 3211.

12. Jeung, G.-H.; Haettel, S. Int J Quantum Chem 1997, 61, 547.

13. Trushin, S. A.; Sugawara, K.; Takeo, H. Chem Phys Lett 1997, 267, 573.

14. Koukounas, C.; Kardahakis, S.; Mavridis, A. J Chem Phys 2005, 123, 074327.

15. Becke, A. D. J Chem Phys 1993, 98, 5648.

16. Perdew, J. P. Phys Rev B 1986, 33, 8822.

17. Adamo, C.; Barone, V. J Chem Phys 1998, 108, 664.

18. Perdew, J. P. Electronic Structure of Solids; Akademic Verlag: Berlin, 1991.

19. Hoe, W.; Cohen, A. J.; Handy, N. C. Chem Phys Lett 2001, 341,319

20. Becke, A. D. Phys Rev A 1988, 38, 3098.

21. Lee, C.; W., Y.; Parr, R. G. Phys Rev B 1988, 37, 785.

22. Perdew, J. P.; Burke, K.; Enzerhof, M. Phys Rev Lett 1996, 77, 3865.

23. Handy, N. C.; Cohen, A. J. Mol Phys 2001, 99, 403.

24. Slater, J. C. Quantum Theory of Molecular and Solids; Vol 4: The Self-Consistent Field for Molecular and Solids; McGrawHill: New York, 1974.

25. Vosko, S. H.; Wilk, L.; Nussair, M. Can J Phys 1980, 58, 1200.

26. Frisch, M. J.; Head-Gordon, M.; Pople, J. A. Chem Phys Lett 1990, 166, 281.

27. Head-Gordon, M.; Head-Gordon, T. Chem Phys Lett 1994, 220,122 .

28. Purvis, G. D.; Bartlett, R. J. J Chem Phys 1982, 76, 1910.

29. Scuseria, G. E.; Janssen, C. L.; Schaefer, H. F., III. J Chem Phys 1988, 89, 1988.

30. Raghavachari, K.; Trucks, G. W.; Pople, J. A.; Head-Gordon, M. Chem Phys Lett 1989, 157, 479.

31. Frisch, M. J.; Trucks, G. W.; Schlegel, H. B.; Scuseria, G. E.; Robb, M. A.; Cheeseman, J. R.; Montgomery, J. A., Jr.; Vreven, T.; Kudin, K. N.; Burant, J. C.; Millam, J. M.; Iyengar, S. S.; Tomasi, J.; Barone, V.; Mennucci, B.; Cossi, M.; Scalmani, G.; Rega, N.; Petersson, G. A.; Nakatsuji, H.; Hada, M.; Ehara, M.; Toyota, K.; Fukuda, R.; Hasegawa, J.; Ishida, M.; Nakajima, T.; Honda, Y.; Kitao, O.; Nakai, H.; Klene, M.; Li, X.; Knox, J. E.; Hratchian, H. P.; Cross, J. B.; Bakken, V.; Adamo, C.; Jaramillo, J.; Gomperts, R.; Stratmann, R. E.; Yazyev, O.; Austin, A. J.; Cammi, R.; Pomelli, C.; Ochterski, J. W.; Ayala, P. Y.; Morokuma, K.; Voth, G. A.; Salvador, P.; Dannenberg, J. J.; Zakrzewski, V. G.; Dapprich, S.; Daniels, A. D.; Strain, M. C.; Farkas, O.; Malick, D. K.; Rabuck, A. D.; Raghavachari, K.; Foresman, J. B.; Ortiz, J. V.; Cui, Q.; Baboul, A. G.; Clifford, S.; Cioslowski, J.; Stefanov, B. B.; Liu, G.; Liashenko, A.; Piskorz, P.; Komaromi, I.; Martin, R. L.; Fox, D. J.; Keith, T.; Al-Laham, M. A.; Peng, C. Y.; Nanayakkara, A.; Challacombe, M.; Gill, P. M. W.; Johnson, B.; Chen, W.; Wong, M. W.; Gonzalez, C.; Pople, J. A. Gaussian 03; Gaussian: Wallingford, CT, 2004.

32. Boys, S. F.; Bernardi, F. Mol Phys 1970, 19, 553.

33. Kim, J.; Lee, H. M.; Suh, S. B.; Majumdar, D.; Kim, K. S. J Chem Phys 2000, 113, 5259.

34. Bach, S. B. H.; Taylor, C. A.; Zee, R. J. V.; Vala, M. T.; Weltner, H. J. J Am Chem Soc 1986, 108, 7104. 